\title{
The IMPACT OF AN IMMERSION PROGRAMME in Cambodia for Australian Pre-Service TEACHERS
}

\author{
Wendy Boyd ${ }^{\mathrm{a}}$ \\ Cathy Lembke \\ Amanda Scott \\ Southern Cross University
}

\begin{abstract}
Australian teachers are required to teach students from diverse cultures, and preservice teachers are reported to feel culturally unprepared. The Australian Government's New Colombo Plan aims to increase pre-service teachers' cultural competency by providing funding for cultural and educational experiences in the Asian-Pacific region. This paper reports on the impact a short-term cultural immersion programme in Cambodia had on the development of cultural competence for ten pre-service teachers. The programme included visits to Cambodian schools and a university, and cultural immersion activities such as Khmer lessons and visiting cultural icons. The cultural competency framework was used to analyse the impact of the programme on pre-service teachers' cultural competence before, during, and after the programme. Findings show that the programme had a significant impact upon meaning-making as the pre-service teachers reflected upon their experiences in Cambodia. The use of focus groups was found to be powerful, supporting pre-service teachers in a safe environment to learn from each other. The article contributes to the growing interest in the effectiveness of immersion programmes in enhancing the development of cultural competency in pre-service teachers. Recommendations include evaluation of the long-term impact of such programmes on pre-service teacher cultural competence.
\end{abstract}

Keywords: cultural impact, pre-service teachers, educational standards, cultural competence

\section{Background}

In today's multicultural classrooms Australian teachers require a deep understanding of cultural diversity and of managing diversity in a culturally competent manner. Being culturally competent involves being aware of one's worldview, having a positive attitude to cultural difference, and developing knowledge of cultural practices across cultures (Department of Education, Employment and Workplace Relations [DEEWR], 2009). Cultural competence is recognized across five of the seven Australian Professional Standards for Teachers (Clinton, Asheton, and Moelle, 2018). Standard 1.3 states that "Graduate teachers must demonstrate knowledge of teaching strategies where students are from diverse linguistic, cultural, religious and socio-economic backgrounds" (Australian Institute for Teaching and School Learning [AITSL], 2014, p.10). Although cultural competence is considered an important capability for effective teachers, research has identified that pre-service teachers (PSTs) in their final year of their teaching degree feel ill-prepared for teaching culturally diverse students and responding to racial prejudice (Australian Council for Educational Research, 2010; Hudson and Hudson, 2011). A lack of knowledge about cultures, confidence in teaching about diverse cultures, and ensuring teaching is authentically linked to culture have been identified as key challenges for

a Correspondence can be directed to: wendy.boyd@scu.edu.au 
Australian teachers (Australian Human Rights Commission, 2016). Opportunities for PSTs are needed in relation to teaching students from culturally diverse backgrounds.

The Australian Government's New Colombo Plan (Department of Foreign Affairs and Trade [DFAT], 2016) is one such initiative. The programme aims to increase PSTs' knowledge of culture by providing short-term scholarships to travel to an Asian-Pacific country and participate in a cultural immersion programme. The programme aims to:

- deepen relationships culturally, educationally, and economically between Australia and these countries; and

- $\quad$ provide opportunities for PSTs to be more employable; and expose PSTs to their new roles as teachers.

Such experiences are likely to be engaging and challenging in many ways-emotionally, socially, cognitively, and culturally (Trede, Bowles, and Bridges, 2013). The DFAT (2016) describes study in these countries as a highly valued endeavour that provides a "rite of passage" (p. 2). Such experiences are likely to challenge PSTs' beliefs, values, and behaviours about culture, and assist them to become culturally competent.

This study presents findings from a 16-day cultural immersion programme for ten PSTs undertaken in November 2014 in Cambodia, and funded by the New Colombo Plan. The aim of this study was to identify the impact of this programme upon the ten PSTs' thinking as they were immersed in Cambodian culture, language, and teaching. Deardorff's (2006) model of cultural competence was the conceptual framework used to analyse the impact of the immersion programme upon PSTs' cultural competence. The findings were based on a questionnaire completed before going to Cambodia, three focus group meetings held in Cambodia, and a post-questionnaire following return to Australia.

Cultural competency, while recognized as a key capability of an effective teacher in the Australian classroom, is currently under-researched (Clinton et al., 2018). This study addresses this gap by extending the theoretical work of Hare Landa, Odòna-Holm, and Shi (2017). Applied knowledge relating to the impact of immersion programmes, such as those in the New Colombo Plan, to enhance cultural competency in PSTs, offer distinctive insight into the process of cultural competency development. The study contributes to the growing interest in the impact of immersion programmes in enhancing the development of cultural competency in PSTs.

The article begins with an overview of the expectations, challenges, and insights of the cultural immersion programme, followed by a description of Cambodia's culture and education system. Deardorff's framework (2006) for understanding and evaluating cultural competency in PSTs is presented and the methodology articulated. The research findings are presented and conclusions and implications are drawn.

\section{Expectations and Challenges of a Cultural Immersion Programme}

The internationalization of education has increased as global mobility has grown (Murray, Hall, Leask, Marginson, and Ziguras, 2011). This mobility is transforming Australian society, requiring teachers to have strategies responsive to students from diverse linguistic, cultural, religious, and socioeconomic backgrounds as per the Australian Professional Standards for Teachers (AISTL, 2014). The DFAT's (2016) initiative to provide opportunities for PSTs to be immersed in Asian-Pacific countries reflects the need to develop ways of thinking, respecting, accepting, and appreciating the diverse cultural practices of the Australian population. However, it remains unclear what the immediate and longterm impact of such short-term mobility programmes are for PSTs, and how they influence their teaching in the long-term (Clinton et al., 2018; Murray et al., 2011).

To understand the impact of PSTs' experiences in a country with a different culture to their home country requires an understanding of what is meant by 'culture'. Culture as described here is "the 
learned and shared values, beliefs, and behaviors of a community of interacting people" (Bennett, 2014, p.1). This process of learning about one's culture incorporates multiple variables (Bennett, 2014). Education and learning are significant in shaping our understanding of culture and humans behave differently in different cultures; that is, culture shapes decision-making about how we choose to see, live, feel, and behave in the world (Wadham, Pudsey, and Boyd, 2007, p.3). Therefore, when PSTs experience a society that has a different culture to their own they can expect to be challenged regarding the behaviors of people in that country, and seek to understand the culture (Wadham et al., 2007). This is likely to shape their view of their own teaching. However, PSTs may experience challenges if they experience an overwhelming culture shock (Marx and Moss, 2011). Disorientation in this new culture may provoke 'outsider status' - a common experience for students in culturally different countries (Trilokekar and Kukar, 2011; Wadham et al., 2007). It is therefore important that a cultural immersion programme provides support for PSTs when they are immersed in another culture to assist them to safely reflect upon their own cultural values, underlying assumptions about cultural practices, and how these align (or not) with their cultural framework and subsequent practices. Fostering critical reflection can enable students to make meaning of their experiences, thus transforming their learning to guide ongoing understanding and appreciation (Mezirow, 1997). Indeed, PSTs have reported: significant benefits of a heightened sense of understanding of their own learning; increased self-confidence, efficacy, and empowerment; and raised awareness of their philosophy of teaching and professional identity (Chinnappan, McKenzie, and Fitzsimmons, 2013; Miller and Gonzalez, 2010; Sharma et al., 2012).

\section{Cambodia's Culture and the Education System}

Cambodia is among the world's poorest nations. It suffered genocide under the four-year Khmer Rouge regime from 1976-1979, during which time between one million and three million people lost their lives-more than a quarter of the population (Heuveline, 1998). Cambodia suffered ensuing civil unrest, thought to have impacted upon social disorientation (Zimmer, Knodel, Kim, and Puch, 2005). This genocide targeted the elite and educated, resulting in the loss of $80 \%$ of the nation's professional classes, including $80 \%$ of the nation's teachers (Brinkley, 2011).

The recovery of the education system has been a slow and difficult process (Brinkley, 2011; Bunlay, Wright, Sophea, Bredenberg, and Singh, 2010), with English-speaking 'international' schools now providing an education for children of the upcoming middle class. English-speaking teachers are often employed from outside of Cambodia to teach in international schools, as Cambodia does not have enough English-speaking teachers. Cambodia is different for Australian PSTs from a cultural, socio-economic, political, linguistic, and educational perspective. These differences can be confronting for PSTs on a short-term immersion programme, and this paper investigates the impact of such a programme upon PSTs' learning.

\section{Methodology}

This research is based in the qualitative paradigm as it focused on questions involving the development of an understanding regarding meaning of people's social worlds (Fossey, Harvey, McDermott and Davidson, 2002). A case study approach was the focus for this study: the case being a New Colombo Plan cultural and educational immersion programme for ten Australian PSTs in Cambodia. Yin (2017) maintains that a case study allows for retaining of meaningful and real-life events in a holistic manner. Methods were selected based on the most suitable tools to address the key research question:

How does a short-term cultural immersion programme impact the development of cultural competence in PSTs? 
According to Clinton et al. (2018), cultural competency is displayed through attitudes, beliefs, and expectations; therefore, formative, self-rating, and self-reflection data collection methods were used to evaluate the characteristics of effective teachers-in this case the characteristic of cultural competence. Deardorff (2006) identifies that questionnaires are a suitable tool for judging an individual's feelings, thoughts, and attitudes relating to the evaluation of the development of cultural competency in an individual. This aligns with the qualitative paradigm of research.

The data sources informed the construction of the case study. Data were collected from the PST participants via questionnaires, and focus group meetings during the cultural immersion period in Cambodia. Questions for these tools were developed drawing from past research (Deardorff, 2006; Hare Landa et al., 2017). The PSTs participated by completing a questionnaire prior to departing Australia, contributing to the three focus groups, and completing a questionnaire upon returning to Australia. Together this mix of data sources provided for a range of PSTs' perspectives over time.

The study followed conventional ethical protocol, including the de-identification of respondents. Ethics approval was received from the authors' institution prior to commencing data collection.

\section{Context}

Thirteen people, including the ten PSTs, two academics and a Cambodian host-were involved in this programme. Ten Australian PSTs were immersed for 16 days in Cambodia with the two academics (two of the authors of this paper) in 2014.

The Cambodian host of the programme introduced the PSTs to the language and culture of Cambodia and shared his experience as a survivor of the Khmer Rouge. The host shared this experience with the group, explaining his perspective of the country's current socio-economic, educational, and political situation. The host organised the visits to five schools; a Cambodian University; and to the sites of cultural interest in Phnom Penh: the Royal Palace, the National Museum, the Killing Fields, S21 Tuol Sleng Genocide Museum, and the Children's Restaurant (a safe haven for impoverished children to have a daily meal).

\section{Theoretical and Analytical Framework}

Being culturally competent involves being aware of one's worldview, having a positive attitude to cultural difference, and developing knowledge of cultural practices across cultures (DEEWR, 2009). Developing cultural competency is considered a complex process, whereby individuals transform from having attitudes of cultural difference, to acquiring cultural knowledge and skills, to intrapersonal awareness which includes adapting to cultural environments, using appropriate communication and having an ethno-relative view, to achieving positive and productive interpersonal interactions (Deardorff, 2006; Hare Landa et al., 2017). This study draws from Hare Landa et al.'s (2017) adaptation of Deardorff's 2006 model of cultural competence development. Hare Landa et al. (2017) investigated the development of cultural competency in future teachers after attending immersion programmes, either domestically or internationally. They found that cultural competence is developed when PSTs apply the knowledge gained from "emotionally compelling, deeply reflected on cultural encounters" (p.21). Their Cultural Competence Framework (CCT) identifies that requisite attitudes, knowledge and comprehension (and skills), desired internal outcomes, and desired external outcomes are useful to measure cultural competency. The current study applied the conceptual framework of Hare Landa et al.'s (2017) cultural competence to analyse PSTs' reflections about experiences to evaluate cultural competency through attitudes, beliefs, and expectations. 


\section{Participants}

The ten PSTs were chosen from 150 applicants across the early childhood, primary, and secondary teacher degrees. The PSTs were successful academic achievers, ranging in age from 20 to 49 years; there were nine females and one male. All students had successfully completed at least one Professional Experience placement in Australia- this was a criteria for selection. For eight of the ten PSTs, this was their final university experience prior to graduation.

All PSTs visited five schools that were related to their teacher training area. All schools were privately-owned and three were international English-speaking schools. These schools conducted all classes in English. The other two schools had English-speaking classes in the morning, and Khmer-speaking classes in the afternoon. The PSTs were welcomed into the classes by the teachers and the Principals, where they observed teaching and assisted as requested. Various expectations were made of them: some PSTs were asked to assist with teaching and interact with the children, while others were invited to teach the class some key aspect of Australia - for example, Australia's national songs such as Waltzing Matilda, or introduce Australia's native animals. Table 1 outlines the participants' characteristics. To protect participant identity the PSTs were given pseudonyms.

Table 1: Participant Demographics

\begin{tabular}{llll}
\hline $\begin{array}{l}\text { Student's name } \\
\text { (Pseudonym) }\end{array}$ & Teacher training area & Gender & $\begin{array}{l}\text { Prior foreign } \\
\text { travel? Yes/No }\end{array}$ \\
\hline Judy & Primary & Female & Yes \\
Maryanne & Primary & Female & Yes \\
Gina & Primary & Female & Yes \\
Jenna & Early Childhood/Primary & Female & Yes \\
Kylie & Early Childhood/Primary & Female & Yes \\
Grace & Secondary (English) & Female & Yes \\
Ellie & Secondary (Music) & Female & Yes \\
Jordan & Secondary (Physics) & Female & No \\
Brian & Secondary (Environmental Science) & Male & Yes \\
Lydia & Secondary (Visual Arts) & Female & Yes \\
\hline
\end{tabular}

\section{Methods: The Questionnaires and Focus Groups}

The pre-questionnaire asked students to identify their expectations and prior knowledge of Cambodia's culture and educational system, as well as their goals for the programme. The postquestionnaire, completed upon return to Australia, asked students to reflect upon their learning regarding the Cambodian educational system, teaching culture in Australia, their goals, and the benefits and challenges of the programme. The questions that were analysed for this study are presented in Table 2. The responses involved short open-ended responses and were qualitative in nature. Thus this study maintained a qualitative approach to the research design as it investigated beliefs, feelings, values and expectations. 
Table 2: Questionnaires

\begin{tabular}{|l|l|}
\hline \multicolumn{2}{|l|}{ Pre-questionnaire } \\
\hline & What do you expect to learn on this trip to Cambodia? \\
\hline & What do you know about education in Cambodia? \\
\hline & Please describe your understanding of teaching diverse cultures in Australia \\
\hline & What are your goals for this trip to Cambodia? (list 3-5) \\
\hline & $\begin{array}{l}\text { What do you think will be the most challenging part of this immersion } \\
\text { programme to Cambodia? }\end{array}$ \\
\hline Post-questionnaire & \\
\hline & What were five key points you learnt on this trip to Cambodia? \\
\hline & Please describe your understanding of teaching diverse cultures \\
\hline & $\begin{array}{l}\text { Will the immersion trip influence your teaching in Australian schools? If so, } \\
\text { in what way? }\end{array}$ \\
\hline & What was challenging in this immersion programme to Cambodia? \\
\hline & $\begin{array}{l}\text { In the pre-survey you were asked about setting goals for the trip. Did you } \\
\text { achieve your goals? Please explain. }\end{array}$ \\
\hline
\end{tabular}

The aim of the three focus groups was to share expectations and experiences, encourage critical reflection, and discuss associated challenges. Focus groups were identified as the ideal way to collect data in this study (Parker and Tritter, 2006). As fostering critical reflection has been shown to support meaning-making to guide ongoing understanding and appreciation (Mezirow, 1997), the researchers intended for the PSTs to experience the benefits of a heightened sense of understanding of their own learning as well as a raised awareness of their philosophy of teaching and professional identity (Chinnappan et al., 2013; Miller and Gonzalez, 2010; Sharma et al., 2012). Thee focus groups were held on days 4, 9, and 15 of the 16-day programme. Each focus group was recorded, capturing the PSTs' initial perceptions (day 4), their thoughts at the mid-way point (day 9), and at the end of the programme (day 15). The PSTs were invited to participate in the focus groups, and were advised that attendance was not compulsory; however, all attended the focus groups and gave consent for recording. The venue chosen was a quiet area of the hotel away from other guests. The researchers posed broad, open-ended prompts to explore the PSTs' experiences of the Cambodian culture and educational system. The broad open-ended questions were similar to those in the pre and post questionnaires (see Table 3). The academics focused on encouraging the PSTs to share their expectations, drawing out the PSTs' views of their experiences in Cambodia to critique their understanding and learning. The academics encouraged every person to speak/respond to others in an effort to ensure the PSTs felt ownership of the discussion. The researchers aimed to provide a platform for the students to safely share their experiences and for this, in turn, to stimulate critical reflection of their values and beliefs. During the focus groups the PSTs took turns to speak one at a time, listening to their colleagues' views, which in turn prompted further responses. These rules were explained at the start of the first focus group.

\section{Data Analysis}

The data from the questionnaires, and the recordings from the focus groups (which were transcribed) were analysed. The complete time frame for data collection was seven weeks. To analyse the data the researchers read, and re-read the data firstly, the participants' views of Cambodia in the pre- 
questionnaire and, secondly, changes in participants' perspectives with the post-questionnaire. Each researcher read and re-read the data through an iterative process. Co-authors' analyses were reviewed until agreement was reached on meaning. The CCT was applied to analyse the data under four headings: requisite attitudes (stage 1), knowledge and comprehension (stage 2), desired internal outcomes (stage 3), and desired external outcomes (stage 4) (Hare Landa et al., 2017). All three authors understood the context for the research as each researcher had been part of the New Colombo Plan cultural immersion programme with PSTs. They thus shared a mutual understanding of the context of being in the cultural and educational system in Cambodia.

\section{Findings and Discussion}

\section{Cultural Competency Framework Stage 1-Requisite Attitudes}

The initial responses from the PSTs in the pre-questionnaire which inquired about expectations and goals during the cultural immersion programme indicated that the PSTs wanted to learn about: Cambodian culture; the education system to inform their own teaching in Australia; and the Khmer language, food, and Cambodian history-with a particular interest in understanding how the recent history of civil unrest in Cambodia has affected the culture and educational systems. The PSTs expected to be challenged about the language, cultural, and educational differences, and the lack of resources for education. For example Judy's response was common regarding expectations:

I expect to observe the different ways in which children learn within their cultural setting. I also hope to learn a variety of different teaching and behaviour management strategies teachers use within this cultural setting. I will also very much enjoy learning more about the Cambodian way of life.

Gina's response to the question about understanding teaching diverse cultures in Australia highlights the understanding that the PSTs had prior to leaving Australia. Gina stated:

Teachers need to be open-minded and challenge their preconceived assumptions about the cultures of their students and families. There needs to be an open communication process between parents, communities, students and teachers. All cultures evolve, therefore teachers also need to evolve and adapt their teaching practices accordingly; there is no such thing as a homogenous society or students.

These comments that were typical of the PST cohort align with the first stage of the cultural competence framework (Hare Landa et al., 2017) regarding requisite attitudes; that is, the PSTs expressed interest in the "diverse, cultural and behavioural norms of students, families and communities" (Hare Landa et al., 2017, p.6), along with a strong desire to know or learn more about Cambodia, its people and the Cambodian education system.

\section{Cultural Competence Framework Stage 2-Knowledge and Comprehension}

Only one of the PSTs (Jordan) had visited Cambodia previously, however she admitted that she did not have a deep understanding of the culture of Cambodia. It was evident at the first focus group (Day 4) that the PSTs felt a sense of initial bewilderment as conveyed by Brian:

I feel so out of place in a way but I have to protect myself-these poor street urchins selling wares. I feel a lot of compassion for them but I am a little bit torn about what, if there's anything, I can do. I am embarrassed to be a wealthy westerner-I really feel like an outsider. 
Here we see Brian expressing what is referred to as 'outsider status', as identified by Trilokekar and Kukar (2011), which aligns with the CCT's second-stage element: "possess an awareness of one's own cultural origins, identity, and practices" (Hare Landa et al., 2017, p.7).Maryanne too shared her thoughts about the people of Cambodia, especially the children:

I couldn't help looking at the children and wonder what life is like through their eyes.

Grace, wondered about the children in Cambodia, reflecting back on how immigrant children who come to Australia feel:

It helps us to understand a little about the children who come to Australia. I realize how lucky we are and I will bring that understanding to my future classrooms.

These PSTs' comments indicate a new knowledge and comprehension of the differences between Australian and Cambodian cultures, while also feeling 'bewildered'. They were trying to be 'in-tune' with the Cambodian culture as they compared Australian culture with what they observed in Cambodia.

Lydia talked about comparing opportunities between Australia and Cambodia:

It's hard not to compare the opportunities we have in Australia to the opportunities they have here. I find myself putting my Western values judgement on their lives. (Lydia)

Remembering that the PSTs had not yet visited a Cambodian school but had witnessed children begging and the impoverished conditions of living in parts of Siem Reap, Maryanne demonstrated a desire to increase her knowledge and comprehension of teaching practices in Cambodia:

I want to know how much of the teaching is influenced by the West? Is it a more Westernized learning focus or is it coming up through the culture? We are learning to be very sensitive to different cultures [in Australia].

Like Maryanne, Jordan also demonstrated her reflections when she contributed her thoughts about being uninformed:

We don't have the cultural background-you can use your teaching practices which are good, but we don't have the cultural knowledge. I feel like I have a different lens on and am learning a lot more than if I were on holiday as a tourist.

It was evident that Lydia, Maryanne, and Jordan felt that Australian culture was the better culture and were questioning how the Cambodian context shaped their views of their own culture. As Wadham et al. (2007) state, "our own beliefs are viewed as natural" (p.21). The sense of being an outsider, and not knowing the cultural values, as expressed by Brian and Maryanne, continued throughout the focus group.

The overall sense of the focus group was that there were many unknowns, with many questions the PSTs did not have answers to. Nonetheless, they were critically reflecting, trying to find meaning as they interpreted their experiences in the Cambodian culture (Mezirow, 1997).

This growing knowledge and comprehension, described in the cultural competence framework as "immersing oneself in knowledge of the sociocultural practices associated with students' heritage countries and ethno-racial identifications and becom[ing] metacognitive of the sociocultural expressions of the dominant culture" (Hare Landa et al., 2017, p.8 ) and recognizing "the diversity of cultural origins identities, and practices that exist in schools, communities, and children, and understanding the sociocultural practices that shape them" (p.8), can be seen from the above comments being expressed by the PSTs. 
Five days later, on day 9 of 16, after the PSTs had visited two international English-speaking schools. The focus group's discussion mostly centered on educational practices that had been observed over the past four days, including teacher-centeredness and behavior management. Ellie commented on classroom management:

$90 \%$ of the classes I saw were disengaged students, especially in music. There were kids not even doing it, hiding in the back corner, climbing over tables-it was chaos. Like assessment, I just don't know how they're assessing. They couldn't answer us either when we said, "How do you know you're effective and your kids are learning?"

The practice of teacher-centeredness as opposed to student-centered learning, such as group work, was an ongoing moot point, as Kylie explained:

They were saying that if they made a mistake, they rubbed it out and showed them the answer rather than trying to explain it. The little girl I saw kept writing three around the wrong way-and she [the teacher] just kept rubbing it out, and she ended up grabbing her hand and writing it with her.

The focus group discussion centered on whether ineffective teaching was related to the teachers being untrained. As Maryanne mentioned:

I think their intentions were good, they just don't have a lot of skills to manage it. There wasn't any real differentiation that I could see. There was no scaffolding or checking. She was just walking around marking the kids' work when they said they were finished, and that was it.

The PSTs wanted to share their observations. Several PSTs made generalisations, concluding that certain observed behavior/s happened in every school across Cambodia. But not all PSTs concurred, offering contradictory examples. For example, after hearing Brian talk about a physics teacher who was teaching incorrect knowledge, Gina provided an example of having observed an 'excellent' lesson:

It had a good introduction, guided discovery, and reflection; and it was on teamwork, so the students actually got to work in groups.

The value of the focus group discussion provided a platform for ongoing critical reflection of making meaning of the PSTs' differing observations. This evidently challenged their desire to generalize about the teaching and teachers. However, Kylie was very sure that children learn best in certain ways; for example, that young children learn best through play. Kylie, an experienced early childhood educator and training to be an early childhood teacher, expressed dismay that young children, 2-3-year-olds, were being given letters to learn and homework:

From an early childhood perspective it's blown me away that there is such a difference between the way we teach and the way they teach, or the way that we educate. We don't actually teach children: they learn through play. Here it's forced upon them.

However, this approach of encouraging children to learn through play was challenged by other PSTs who recalled the academic success of Asian school students in Australia, and wondered whether this was a result of this early academic approach. Even Kylie reflected on this:

You do question whether the Australian way is right, or their way is right, because are they academically better off? Even the handwriting in the year one class was amazing, compared to a year one Australian class room. The pencil grip was amazing. I wondered whether it's 
because they spend so much time explicitly teaching that they're able to hold the pencil grip. You look at Australia-some kids in year six still can't even hold a pencil.

This focus group exemplified PSTs being both critical and supportive of Cambodian teaching practices. These responses aligned with stage 2 of the CCT framework, highlighting the ongoing aspect of developing a cultural awareness that will influence a PST's role as an educator. In particular, they show a further deepening of their knowledge and comprehension, where they are "constructing a sociolinguistic knowledge of both dominant and non-dominant linguistic practices used within schools and classrooms with the 'emerging awareness of the cultural norms and practices in cultural groups other than one's own'” (Hare Landa et al., 2017, p.8).

\section{Cultural Competency Framework Stage 3-Desired Internal Outcomes -Adaptability}

By day 15 (of 16) of the cultural and educational immersion programme the PSTs had visited five schools, and completed cultural experiences within Cambodia (see table 1). They had visited the Royal Palace, the National Museum, the Genocide Museum, and the Killing Fields. The PSTs' reflections on their immersion programme demonstrate that their learning changed their values while being in Cambodia. Their reflections demonstrated PSTs suggesting evidence of the characteristics of stage 3 of the cultural competence framework. For example "recognizing that diverse pedagogical practices occur in different cultural contexts" (Hare Landa et al., 2017, p.9) and accepting this as something that can be "embraced when facing cultural norms that are different from one's own" (p.9), was evident when Judy explained how observing the teachers had taught her new ideas for her teaching:

It was really nice to see the individual teachers had their own teaching styles... and to see a variety of different teaching styles for me has been really good, it sort of made my learning a little bit more cemented...I was sort of having light bulbs going off and thinking "Oh I could do this".

Jenna also reflected on the diversity of teaching practices and how she had developed an understanding of the Cambodian worldview:

It's been just very diverse, and I think that's been a really good thing to see. Maybe some teaching styles I won't embrace but then [there are] others that I might.

Jenna's quote not only demonstrates that adaptability, but it also shows how Jenna had developed deeper knowledge and comprehension of the cultural and education system of Cambodia, as explained by stage 2 of the CCT. There was an ongoing sense of acceptance of difference as the PSTs recognized that teaching practices differed significantly both within Cambodia, and between Cambodia and Australia. Kylie continued to question and reflect upon the best way for young children to learn:

They [children] are actually able to comprehend what they are taught and it's just drilled into them. It might be the right way for them. I don't know. Are we doing it the wrong way? Is this why you see your Asian students excelling because they are drilled from such a young age?

Maryanne described how her perspectives on the education practices had developed and changed, demonstrating the stage 3 CCT characteristic of "recognizing that pedagogical practices that occur in one cultural context may be transferable to others" (Hare Landa et al., 2017, p.8), but also demonstrating her knowledge and comprehension (Stage 2 of the CCT) stating:

At first I was comparing how I would be instructing the class and the strategies I would use.

Then I stopped and asked myself: why are they doing it the way they're doing it? I guess when 
I was sort of being critical about the teaching, the school's structure, the teaching method, then I think particularly after getting a glimpse of what happened in the Pol Pot era and how the education was pretty much wiped out, it's given me appreciation of how they are performing. It's given me more insight to their challenges, so I feel that I've got a lot of value out of that I can take back.

Acknowledging the Cambodian contexts of the schools the PSTs had visited-that is, Englishspeaking international schools catering for the middle classes of Cambodia-the PSTs identified the tensions within these schools with unqualified teachers, who mostly were not from Cambodia. Parents choose these schools for their children to learn English, yet many teachers are unqualified to teach. These tensions are an example of embracing an "ethno-relative perspective when facing cultural norms that are different from one's own" (Hare Landa et al., 2017, p.8). For example, Lydia continued to feel that the students were very compliant, and wondered if this was a function of Cambodian culture:

What struck me the most was how compliant the students were. Like in the older schools, they listened to instructions and followed through. They barely mucked up. And in class today, one of the teachers asked the students how they could make their classroom better and what things would make Phnom Penh better. They were all looking at each other, so it wasn't an easy conversation. But there was one brave kid. So I wonder about that whole compliance in culture, are they are a very compliant culture?

Grace demonstrated how she had the capability to adjust and adapt to cultural differences, comparing the Cambodian culture to Australian culture, which aligns with the CCT's stage 3 element of "adapting to the dynamic expression of cultures within educational institutions, communities and classrooms and flexibly accommodating intercultural complexity" (Hare Landa et al., 2017, p.8), stating:

I think they embed culture really well here. And they embrace their culture. Whereas I don't feel we do it quite as well in Australia. Like someone said to me: What's the Australian dance? Well, what is the Australian dance? Culture in Australia, apart from embracing Indigenous culture, people are unaware of it.

When the PSTs were asked what advice they would give to another group of PSTs coming to Cambodia, Maryanne's comment provides an apt summary of the PSTs' thinking and aligns closely with the features of stage 3 of the CCT:

Think broadly. Question your beliefs, your values against what you do in the classroom, what you see. And then challenge and reflect. You really have to reflect on practices. And then once you go home I think that process will continue and continue, and it will be good for our professional development for a long time to come.

During the focus groups the power of this discussion approach was clear: the PSTs appeared to be learning from each other. One would begin talking about a topic and this would cause a flurry of comments from others. The PSTs clearly felt safe to share their thoughts with each other and the academics.

Stage 3 of the CCT (desired internal outcomes - that being primarily adaptability) was shown by all ten students. The emergence of empathy in relation to the way the PSTs were now seeing Cambodia and its people was also evident in the data collected from this focus group. Being able to "empathise with children and families about their lives" and also to be able to "embrace an 
ethnorelative perspective when facing cultural norms that are different to one's own" (Hare Landa et al., 2017, p.8) are two very significant features of stage 3 of the CCT.

Analysis of the post-questionnaire (see table 2) show PSTs reported feeling more competent after the cultural immersion programme regarding education and culture in Cambodia, having overcome the 'outsider status' feeling (Trilokekar and Kukar, 2011). The PSTs said they felt more confident communicating with students of diverse backgrounds, however this confidence seemed to not translate to teaching in Australia, even though all PSTs agreed that Australia had many diverse cultures. This is a point to ponder, and a possible direction for future research; because of this experience, do the PSTs feel less confident teaching diverse cultures in Australia because they have a deeper understanding of the complexity of culture?

Nonetheless, the PSTs said they felt they could communicate teaching and learning experiences more effectively-including diverse cultures-and that they could relate well to students from diverse cultures. This suggests characteristics of stage 4 of the CCT; that is, as "an educator that they could proactively and responsibly negotiate intercultural contexts" (Hare Landa et al., 2017, p.9), as they begin to work in educational settings with communities and individual students. This presents as a limitation of this study- the self-reporting on the post-questionnaire is contradictory. Perhaps this is due to the relief the PSTs felt about returning to Australia, a common experience to be back on one's own culture after being confronted with cultural diversity.

\section{Cultural Competence Framework Stage 4 - Desired External Outcomes}

A significant shift appeared to occur in PSTs' beliefs: that they felt more competent to provide feedback to students from diverse cultures. The PSTs concluding remarks demonstrate how their beliefs and values about culture and education before, during, and after the cultural and educational immersion programme had changed. This suggests an alignment with stage 4 of the CCT regarding the growing capacity to "achieve valued goals through sustained positive and productive interpersonal communications, while negotiating cultural norms and practices in intercultural contexts" (Hare Landa et al. 2017, p.9). The comments below from the post-questionnaire suggest the deep learning that occurred and the impact of this cultural and educational programme. Lydia wrote about the challenges of wanting to compare her ideology with Cambodian practices:

The most challenging part of the immersion programme to Cambodia was seeing educational systems and practices that did not align with my own ideas about best practice. It was difficult to keep an open mind without giving advantage to my own Western cultural ideas and beliefs.

Maryanne expressed revelations of understanding the importance for teachers to be aware of students' cultural backgrounds:

Ideology driving education is shaped by so many factors. Just because something works in the West does not mean we can transpose it into the East and vice versa. It would be wise and mindful for a teacher and school to gain understanding for the education background, experience, and ethos that has shaped each student's learning.

Kylie commented on how the programme had forced her to challenge her beliefs and values about pedagogy:

This immersion programme has helped me look deeply into my pedagogical practices and helped me form ideas to share with my team on education. I thought I was very open-minded about culture, but this trip proved me wrong. When I was visiting each school I found myself questioning the Australian way. Is our way of teaching the right way? Are our children allowed enough freedom and choice? 
The above comments highlight the journey these PST's took over this short-term cultural immersion programme, which from the data presented suggests that the programme had an impact upon their learning, and challenged their attitudes, values and beliefs. The data suggests that many PSTs were exhibiting the "requisite intrapersonal and interpersonal skills of cultural competence... and ...the ability to engage in positive and productive interpersonal interactions" (Hare Landa et al., 2017, p.5), however it is important to be mindful of the limitations of this study which will be further discussed in the conclusion.

\section{Limitations, Recommendations and Conclusion}

This study aimed to identify the impact of a cultural and educational immersion programme in Cambodia on the development of cultural competence for ten PSTs. When analysed through the CCT, the data from the participants suggest that this short-term cultural immersion programme had an impact upon the development of the PSTs' cultural competence (Hare Landa et al., 2017). Indeed several PSTs in this study experienced this immersion programme as being 'life-changing'. It is possible to conclude that the PSTs developed cultural competency to some degree, and different aspects of cultural competency to different degrees, such as having a knowledge and comprehension of the educational system in English speaking schools in Cambodia. That said, the PSTs' cultural competence development appeared to align with stages in the CCT, moving from "foundational attitudes toward cultural differences, to the acquisition of cultural knowledge, to intrapersonal awareness, and, finally, to the ability to engage in positive and productive interpersonal interactions" (Hare Landa et al., 2017, p.5). However there are limitations in this study that need to be addressed.

It is not possible to conclude that PSTs attained knowledge and comprehension (CCT2) of the Cambodian cultural and educational system. However it is clear that the cultural immersion programme had an impact upon PSTs' attitudes to cultural diversity. They were developing knowledge of cultural practices across Cambodian culture (DEEWR, 2009) while demonstrating uncertainty and grappling with becoming knowledgeable in this context.

The study was limited, as the existing values, morals, and beliefs of the PSTs were not fully considered. While an effort was made to capture the attitudes of the PSTs prior to travelling to Cambodia, it is not possible to conclude that the programme challenged the internal assumptions necessary to develop a high level of cultural competency. This requires ongoing professional learning in Australia. As Australia is a multicultural country, the opportunities to experience diverse cultures exist however, they need to be made more explicit in the curriculum. Otherwise Australia will continue to perpetuate the finding that teachers feel ill-prepared (Hudson and Hudson, 2011) to teach culturally diverse students.

The cultural competency framework developed by Deardorff (2006) provided a useful model to analyse the recorded experiences of PSTs in a cultural immersion programme in Cambodia. Exposure to a culture different to one's own is bound to raise many challenges to one's values and beliefs. Over time these challenges will be assimilated and understood. This programme was for a short time. This is a limitation of the study. The authors plan future research to investigate long term impact of this programme. Additionally, this study is now part of a longitudinal five year study where further data collected will build a larger sample that may help to address the limitations of this initial study.

What this study did find is that, in the case of this Cambodian experience, the benefits of the programme for PSTs offered by the Australian Government, facilitated the learning described in the AITSL standards, as necessary to develop culturally competent teachers. Consequently, programmes such as the New Colombo Plan may be seen as a means to address the gap that currently exists between PSTs and university education courses, offering PSTs opportunities for authentic engagement for learning and transformation, leading to Australian teachers with enhanced cultural competence. It is currently not possible to offer such programmes to all training teachers. It was clear that the PSTs initially lacked knowledge around Cambodian culture and so Australia could consider developing a broader curriculum to enable all PSTs to undergo professional learning in cultural competency. 


\section{References}

Australian Institute for Teaching and School Learning (AITSL). (2014). Australian Professional Standards for Teachers. Available at http://www.aitsl.edu.au/ [Accessed 28 January 2019].

Australian Council for Educational Research. (2010). Australasian Questionnaire of Student Engagement (AUSSE) (2010). Available at http://ausse.acer.edu.au/index.php?option=com_co ntent\&view=category\&layout=blog\&id=3\&Itemid=4 [Accessed 14 January 2019].

Australian Human Rights Commission. (2016). Building Belonging. Available at https://www. humanrights.gov.au/.../buildingbelonging-2016.09.16 [Accessed 14 January 2019].

Bennett, J. M. (2014). Intercultural competence: Vital perspectives for diversity and inclusion. In B. M. Fredman and B. R. Deane (Eds.), Diversity at Work: The Practice of Inclusion. San Francisco: Jossey-Bass, pp.155-202.

Brinkley, J. (2011). Cambodia's Curse. New York: Public Affairs.

Bunlay, N., Wright, E., Sophea, H., Bredenberg, K. and Singh, M. (2010). Active Learning Pedagogies as Reform Initiative. Available at http://www.equip123.net/docs/E1-ActiveLearningPedagogyCambodia.pdf. [Accessed 30 June 2018].

Chinnappan, M., McKenzie, B. and Fitzsimmons, P. (2013). Pre-service teachers' attitudes towards overseas professional experience: Implications for professional practice. Australian Journal of Teacher Education, 38(12), pp. 36-54.

Clinton, J., Aston, R. and Koelle, M. (2018). Investigating the Key Characteristics of Effective Teachers: A Systematic Review. Canberra: Department of Education and Training.

Deardorff, D. K. (2006). Identification and assessment of intercultural competence as a student outcome of internationalization. Journal of Studies in International Education, 10(3), pp. 241-266.

Department of Education, Employment and Workplace Relations (DEEWR). (2009). The Early Years Learning Framework. Canberra: Commonwealth of Australia.

Department of Foreign Affairs and Trade (DFAT). (2016). New Colombo Plan. Available at http://dfat. gov.au/people-to-people/new-colombo-plan/about/Pages/about.aspx

[Accessed 13 December 2018].

Fossey, E., Harvey, C., McDermott, F. and Davidson, L. (2002). Understanding and evaluating qualitative research. Australian and New Zealand Journal of Psychiatry, 36(6), pp. 717-732.

Hare Landa, M., Odòna-Holm, J. and Shi, L. (2017). Education abroad and domestic cultural immersion: A Comparative study of cultural competence among teacher candidates. The Teacher Educator, 52(3), pp. 250-267.

Heuveline, P. (1998). Towards the demographic reconstruction of a decade of Cambodian history. Population Studies, 52(1), pp. 49-65.

Hudson, P. and Hudson, S. (2011). Partners in Education: The Teacher Education Done Differently Project. Paper presented at the Australian Teacher Education Association Conference, Melbourne.

Marx, H. and Moss, D. (2011). Please mind the culture gap: Intercultural development during a teacher education study abroad program. Journal of Teacher Education, 62(1), pp. 35-47.

Mezirow, J. (1997). Transformative learning: Theory to practice. New Directions for Adult and Continuing Education, 1997(74), pp. 5-12.

Miller, K., and Ganzalez, A. (2010). Challenges and Rewards associated with Service-learning in International Contexts. Available at journals.sfu.ca/ijrslte/index.php/IJRSLTE/article/ download/20/pdf_3. [Accessed 30 June 2018].

Murray, D., Hall, R., Leask, B., Marginson, S. and Ziguras, C. (2011). State of Current Research in International Education. Available at www.Ihmartininstitute.edu.au/documents/publications/ murraystatepaper.pdf [Accessed 30 June 2018].

Parker, A. and Tritter J. (2006). Focus group method and methodology: Current practice and recent debate. International Journal of Research \& Method in Education, 29(1), pp. 23-37 
Patton, M.Q. (1999). Enhancing the quality and credibility of qualitative analysis. Health Service Research, 34(5), pp. 1189-1208

Sharma, S., El-Atwani, K., Rahatzad, J., Ware, J., Phillion, J. and Malewski, E. (2012). How disorienting experiences in informal learning contexts promote cross-cultural awareness in preservice teachers. LEARNing Landscapes, 5(2), pp. 281-293.

Trede, F., Bowles, W., and Bridges, D. (2013). Developing intercultural competence and global citizenship through international experiences: Academics' perceptions. Intercultural Education, 24(5), pp. 442-455.

Trilokekar, R., and Kukar, P. (2011). Disorienting experiences during study abroad. Teaching and Teaching Education, 27(7), pp. 1141-1150.

Wadham, B., Pudsey, J. and Boyd, R. (2007). Culture and Education. French's Forest, NSW: Pearson Education Australia.

Yin, R. (2017). Case Study Research and Applications: Design and Method (6 $6^{\text {th }}$ ed.). Thousand Oaks, CA: Sage Publications

Zimmer, Z., Knodel, J., Kim, K.S. and Puch, S. (2005). The impact of past conflicts and social disruption on the elderly in Cambodia. Population and Development Review, 32(20), pp. 333-360. 
